\title{
Corrigendum: Voltage-controlled enzymes: the new Janus Bifrons
}

\section{Carlos A. Villalba-Galea *}

Department of Physiology and Biophysics, Virginia Commonwealth University School of Medicine, Richmond, VA, USA

Keywords: VSD relaxation, Ci-VSP, voltage-sensitive phosphatases, sensing currents, hysteresis

\section{A Corrigendum on}

Voltage-controlled enzymes: the new Janus Bifrons

by Villalba-Galea, C. A. (2012). Front. Pharmacol. 3:161. doi: 10.3389/fphar.2012.00161

Due to an error, there is an mistake in panel $\mathrm{C}$ of the original version of Figure 1. The correct version of Figure 1 is presented below. The figure legend has been updated to improve readability, but the message remains unaltered.

\section{OPEN ACCESS}

Edited by:

Mohamed Chahine Laval University, Canada

Reviewed by:

Michael E. O'Leary, Cooper Medical School of Rowan

University, USA

*Correspondence: Carlos A. Villalba-Galea, cavillalbaga@vcu.edu

Specialty section: This article was submitted to Pharmacology of Ion Channels and

Channelopathies, a section of the journal Frontiers in Pharmacology

Received: 20 April 2015 Accepted: 07 May 2015 Published: 29 May 2015

Citation:

Villalba-Galea CA (2015) Corrigendum: Voltage-controlled enzymes: the new Janus Bifrons.

Front. Pharmacol. 6:109. doi: 10.3389/fphar.2015.00109
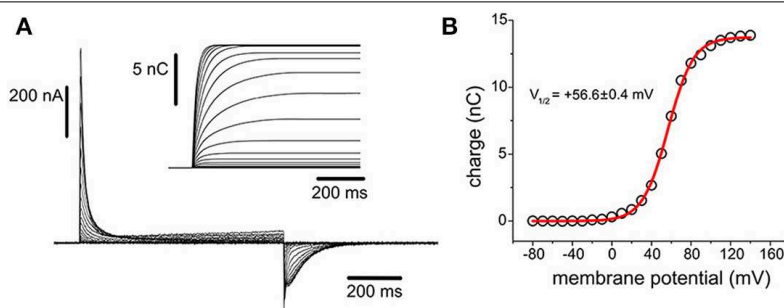

C

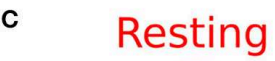

Active
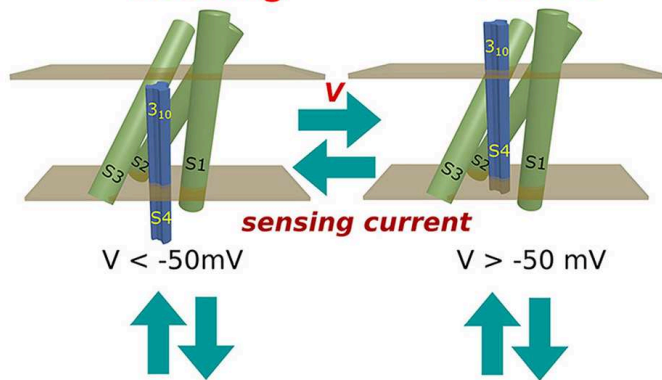

Relaxed Resting
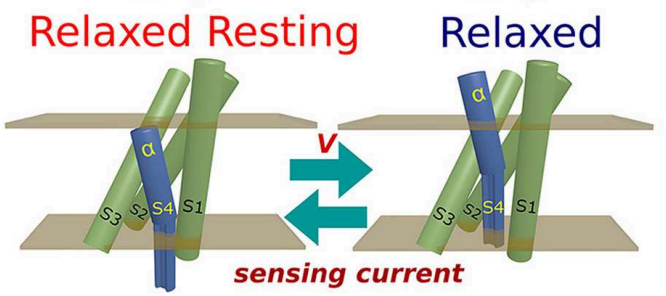

FIGURE 1 | Continued 


\section{FIGURE 1 | Continued}

(A) Ci-VSP-C363S sensing currents recorded from Xenopus oocytes using the Cut-Open Voltage-Clamp technique (Taglialatela et al., 1992; Stefani and Bezanilla, 1998). The holding potential (HP) was set to $-60 \mathrm{mV}$, and $\mathrm{ON}$-sensing currents were evoked by $800 \mathrm{~ms}$-test pulses ranged from $-80 \mathrm{mV}$ to $+140 \mathrm{mV}$. OFF-sensing currents were recorded at $-60 \mathrm{mV}$. Numerical integration of the $\mathrm{ON}$-sensing currents (inset) was performed with a package developed by the author using the programming language Java. (B) The calculated net charges were plotted against the voltage applied during the corresponding test pulse. The charge $(\mathrm{Q})$ vs. potential $(\mathrm{V})$ relationship was fitted to a Boltzmann distribution (see text). For this particular example, the fitted half-maximum potential was $+56.6 \pm 0.4 \mathrm{mV}$. (C) Minimum scheme describing the electrical behavior of the voltage sensing domain of Ci-VSP: At potentials below $-50 \mathrm{mV}$, the VSD resides with high probability in the resting state. Upon changing the membrane potential to more positive voltages, sensing currents were produced as sensing charges moves down the electrical gradient, leading the VSD into the active state. If the membrane potential is above $+50 \mathrm{mV}$, a secondary, voltage-independent transition is observed. During this process, called relaxation (see text), the relaxed state is populated. Transitions between the resting and active state may occur while the S4 segment is in a $3_{10}$ helix conformation. However, transit into the relaxed states may be accompanied by a transformation of the upper part of the S4 segment into an $\alpha$-helix. Repolarization of the plasma membrane drives the return of the VSD to the resting state. This transition is achieved through a hypothetical relaxed-resting state.

\section{Acknowledgments}

Thanks to Dr. Eduardo Rios for his comments.

\section{References}

Stefani, E., and Bezanilla, F. (1998). Cut-open oocyte voltage-clamp technique. Methods Enzymol. 293, 300-318.

Taglialatela, M., Toro, L., and Stefani, E. (1992). Novel voltage clamp to record small, fast currents from ion channels expressed in Xenopus oocytes. Biophys. J. 61, 78-82.
Conflict of Interest Statement: The author declares that the research was conducted in the absence of any commercial or financial relationships that could be construed as a potential conflict of interest.

Copyright (c) 2015 Villalba-Galea. This is an open-access article distributed under the terms of the Creative Commons Attribution License (CC BY). The use, distribution or reproduction in other forums is permitted, provided the original author(s) or licensor are credited and that the original publication in this journal is cited, in accordance with accepted academic practice. No use, distribution or reproduction is permitted which does not comply with these terms. 